\title{
LDL cholesterol counteracts the antitumour effect of tyrosine kinase inhibitors against renal cell carcinoma
}

\author{
Sei Naito ${ }^{1,5}$, Peter Makhov ${ }^{1,5}$, Igor Astsaturov ${ }^{2}, K_{\text {Konstantin Golovine }}{ }^{1}$, Alexei Tulin ${ }^{3}$, Alexander Kutikov ${ }^{4}$, \\ Robert G Uzzo ${ }^{4}$ and Vladimir M Kolenko*,1 \\ ${ }^{1}$ Cancer Biology Program, Fox Chase Cancer Center, Philadelphia, PA 19111, USA; ${ }^{2}$ Department of Hematology/Oncology, \\ Molecular Therapeutics Program, Fox Chase Cancer Center, Philadelphia, PA 19111, USA; ${ }^{3}$ Cancer Epigenetics Program, \\ Fox Chase Cancer Center, Philadelphia, PA 19111, USA and ${ }^{4}$ Division of Urologic Oncology, Department of Surgery, Fox Chase \\ Cancer Center, Philadelphia, PA 19111, USA
}

Background: Treatment with tyrosine kinase inhibitors (TKIs) significantly improves survival of patients with renal cell carcinoma (RCC). However, about one-quarter of the RCC patients are primarily refractory to treatment with TKIs.

Methods: We examined viability of RCC and endothelial cells treated with low-density lipoprotein (LDL) and/or TKls. Next, we validated the potential role of PI3K/AKT signalling in LDL-mediated TKI resistance. Finally, we examined the effect of a high-fat/ high-cholesterol diet on the response of RCC xenograft tumours to sunitinib.

Results: The addition of LDL cholesterol increases activation of PI3K/AKT signalling and compromises the antitumour efficacy of TKIs against RCC and endothelial cells. Furthermore, RCC xenograft tumours resist TKIs in mice fed a high-fat/high-cholesterol diet.

Conclusions: The ability of renal tumours to maintain their cholesterol homoeostasis may be a critical component of TKI resistance in RCC patients.

Renal cell carcinoma (RCC) is the most common form of kidney cancer. It is categorised into various subtypes, with clear cell RCC (ccRCC) representing about $85 \%$ of all RCC tumours (Shuch et al, 2015). The use of tyrosine kinase inhibitors (TKIs) has resulted in doubling of the progression-free survival and significant gains in the overall survival (Rini, 2010). However, complete and durable responses have been noted in only a few cases (Buczek et al, 2014). Furthermore, 26\% out of 1056 patients treated with sorafenib and sunitinib were primarily refractory to treatment (Park et al, 2012).

In addition to the inhibition of angiogenesis, TKIs also exert a direct cytotoxic effect on tumour cells (Gotink and Verheul, 2010; Makhov et al, 2012). Notably, intra-tumour sunitinib levels are much higher than peak serum levels (Gotink et al, 2011; Makhov et al, 2012; Adelaiye et al, 2015). Our current findings demonstrate that low-density lipoprotein (LDL)-mediated activation of PI3K/ AKT signalling coincides with the compromised activity of TKIs against RCC and endothelial cells. Furthermore, the present study establishes, for the first time, the role of hyperlipidaemia in TKI resistance in an animal model of human RCC.

\section{MATERIALS AND METHODS}

Cells and culture conditions. The SK-45 human ccRCC cell line (Canter et al, 2011) was a kind gift of Dr Testa (Fox Chase Cancer 
Center (FCCC)). The PNX0010 human ccRCC cell line (Kirsanov et al, 2014) was a kind gift of Dr Vladimir Khazak (Priaxon Inc.). The HUVEC cell line was obtained from ATCC. Cells were cultured as described previously (Golovine et al, 2008).

Antibodies and reagents. Antibody against $\beta$-actin, AKT inhibitor IV, LY294002, and 2-hydroxypropyl- $\beta$-cyclodextrin (HPCD) were obtained from Santa Cruz Biotechnology (Dallas, TX, USA). Antibodies to Akt, p-Akt (S473 and T308), p-MEK1/2, MEK, p-ERK1/2, ERK, and p-4E-BP1 were obtained from Cell Signaling Technology (Beverly, MA, USA). Low-density lipoprotein was obtained from Alfa Aesar (Tewksbury, MA, USA). Sunitinib, sorafenib, pazopanib, and lapatinib were obtained from LC Laboratories (Woburn, MA, USA).

Western blot analysis. Western blot analysis was performed as described previously (Golovine et al, 2008).

Cell viability. Cell viability was analysed by CellTiter Blue assay (Promega, Madison, WI, USA).

In vivo studies. All animal studies were performed under approval from the FCCC Institutional Animal Care and Use Committee, and followed FCCC and NIH guidelines. Six-week-old male C.B17/ Icr-scid mice were placed on either regular 2018SX diet or high-fat/ high-cholesterol TD.96121 diet (Harlan Teklad, Indianapolis, IN, USA). Two weeks later, $1 \times 10^{6}$ PNX0010 cells were inoculated s.c. in the flank region of the mice. When tumours reached a mean volume of about $100 \mathrm{~mm}^{3}$, the mice were randomly assigned to the treatment and control groups ( $n=5$ mice per group). The mice were treated with either PBS (vehicle) or sunitinib $\left(40 \mathrm{mg} \mathrm{kg}^{-1}\right.$, 5 days per week, p.o.) as described earlier (Makhov et al, 2012). Tumours were measured twice weekly and their volumes were calculated by the formula: (volume $=0.52 \times(\text { width })^{2} \times$ length). Serum LDL and total cholesterol levels were examined at Charles River Laboratories (Wilmington, MA, USA). Formalin-fixed and paraffin-embedded xenograft tumours were cut in five micron sections and immunostained with anti-phospho-Akt (S473) or anti-phospho-4E-BP1 (T37/46) antibodies at the FCCC Histopathology Facility. Imaging was performed using Nicon Eclipse 80i microscope. Images were acquired using $\times 20$ atmospheric lens and analysed by NIS-Elements BR4.13.00 software package (Nikon Instruments Inc., Melville, NY, USA).

Statistical analysis. Statistical analysis was performed using a twosided Student's $t$-test. A $P$-value of $<0.05$ was considered statistically significant.

\section{RESULTS}

Our recent studies demonstrate that the augmented activation of PI3K/AKT signalling promotes resistance to sunitinib in genitourinary tumours. The addition of purified LDL dramatically increased AKT phosphorylation in established SK-45 and patientderived PNX0010 ccRCC cell lines in a dose- and time-dependent manner (Figure 1A). The activation of AKT was validated by augmented phosphorylation of its downstream target proteins, GSK-3 $\beta$ and p70S6K (Figure 1A). Next, we investigated whether LDL-mediated activation of AKT signalling interferes with the antitumour activity of TKIs. To demonstrate that our observations are not limited to the specific pharmacological agent, we treated cells with several clinically relevant TKIs such as sorafenib, pazopanib, lapatinib, and sunitinib. The addition of LDL markedly rescued viability of SK-45 cells treated with all TKIs (Figure 1B). This effect was specific for TKIs as the antitumour efficacy of doxorubicin and docetaxel was not compromised in the presence of LDL (Figure 1C). Low-density lipoprotein also rescued the viability of HUVEC cells treated with sorafenib (Figure 1D). These findings are of particular
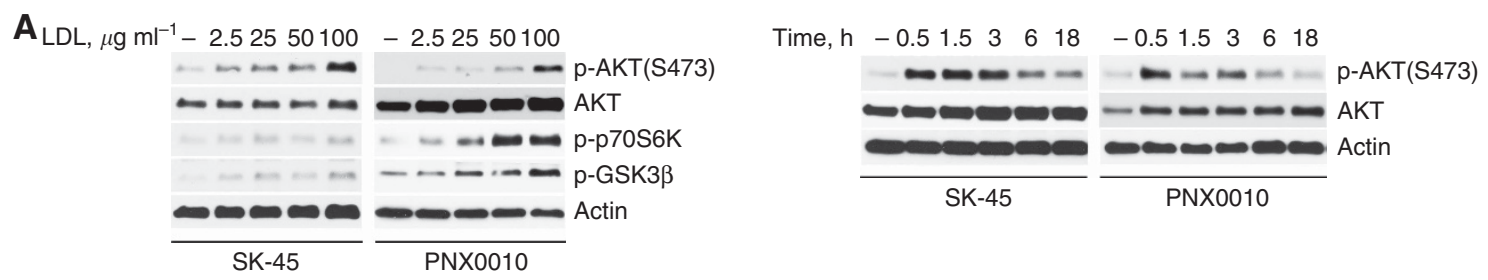

B
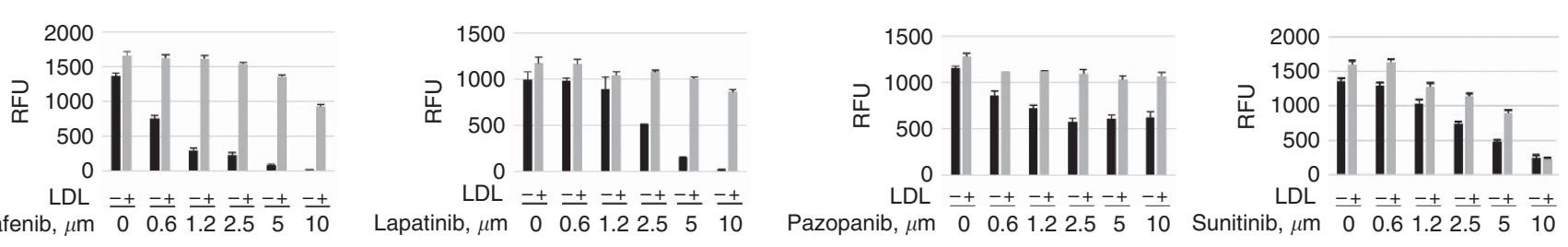

C

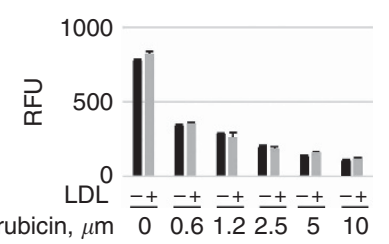

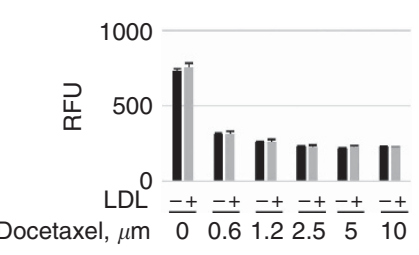

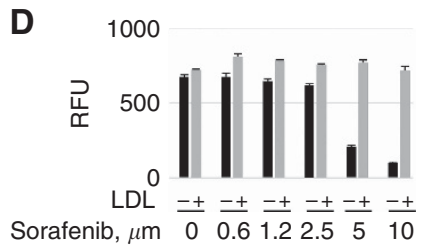

Figure 1. LDL activates AKT signalling and compromises the antitumour efficacy of TKIs. (A) Dose- and time-dependent activation of AKT by LDL. SK-45 and PNX0010 RCC cells were treated with the indicated concentrations of LDL for $1.5 \mathrm{~h}$ or with LDL $\left(100 \mu \mathrm{g} \mathrm{ml}^{-1}\right)$ for the indicated periods of time. (B) LDL restores viability of SK-45 RCC cells treated with TKIs. Cells were cultured with the indicated concentrations of TKIs in the presence or absence of LDL $\left(100 \mu \mathrm{g} \mathrm{ml}^{-1}\right)$ for $72 \mathrm{~h}$. Cell viability was analysed by CellTiter Blue assay. Results are expressed as the mean $(n=3) \pm \mathrm{s} . e . \mathrm{m}$. (C) LDL does not reinstate viability of RCC cells treated with either doxorubicin or docetaxel. SK-45 cells were cultured with the indicated concentrations of doxorubicin or docetaxel in the presence or absence of LDL (100 $\mu \mathrm{g} \mathrm{ml}^{-1}$ ) for $72 \mathrm{~h}$. (D) LDL (100 $\left.\mu \mathrm{g} \mathrm{ml}^{-1}\right)$ rescues the viability of HUVEC cells treated with sorafenib. RFU, relative fluorescence units. 

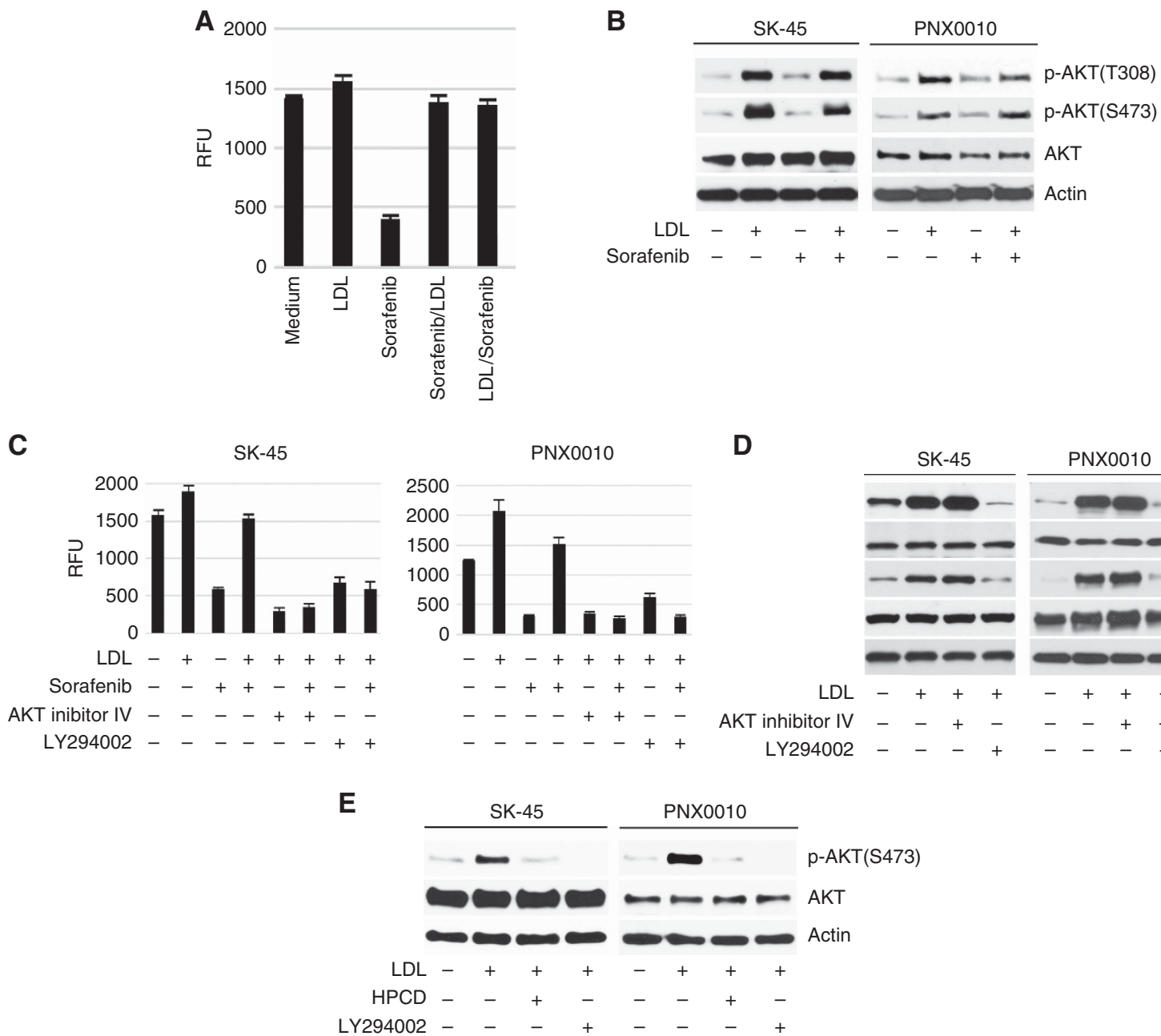

Figure 2. Inhibition of PI3K/AKT signalling enhances the antitumour efficacy of TKls in the presence of LDL. (A) SK-45 cells were pre-treated with sorafenib $(1 \mu \mathrm{M})$ for $3 \mathrm{~h}$ followed by the addition of $\mathrm{LDL}\left(100 \mu \mathrm{g} \mathrm{ml}^{-1}\right)$, or in the reverse order. Cell viability was analysed by CellTiter Blue assay. (B) Sorafenib does not affect LDL-induced activation of AKT. SK-45 cells were pre-treated with sorafenib $(2.5 \mu \mathrm{m})$ for $1 \mathrm{~h}$ followed by the addition of LDL $\left(100 \mu \mathrm{g} \mathrm{ml}^{-1}\right)$ for $1 \mathrm{~h}$. (C) SK-45 and PNX0010 cells were pre-incubated with AKT inhibitor IV (1 $\left.\mu \mathrm{m}\right)$ or PI3K inhibitor LY294002 (10 $\left.\mu \mathrm{M}\right)$ for $1 \mathrm{~h}$ followed by incubation with sorafenib $(1 \mu \mathrm{M})$ and/or LDL $\left(100 \mu \mathrm{g} \mathrm{ml}^{-1}\right)$ for $72 \mathrm{~h}$. Cell viability was analysed by CellTiter Blue assay. (D) The addition of LDL activates MEK/ERK signalling. SK-45 and PNX0010 cells were pre-incubated with AKT inhibitor IV (1 $\mu \mathrm{M})$ or LY294002 $(10 \mu \mathrm{m})$ followed by the addition of LDL $\left(100 \mu \mathrm{g} \mathrm{ml}^{-1}\right)$ for $1 \mathrm{~h}$. (E) The effect of HPCD on LDL-mediated AKT activation in RCC cells. SK-45 and PNX0010 cells were pre-treated with LDL $\left(100 \mu \mathrm{g} \mathrm{ml}{ }^{-1}\right)$ for $1 \mathrm{~h}$ followed by the addition of HPCD (10 mM) for $2 \mathrm{~h}$. LY294002 (10 $\left.\mu \mathrm{M}\right)$ was used as a control in this experiment.

importance given the dual anti-angiogenic and direct antitumour mechanisms of TKIs action (Xin et al, 2009; Gotink and Verheul, 2010; Makhov et al, 2012).

Low-density lipoprotein may compromise the antitumour activity of TKIs by interfering with TKIs' cellular uptake. To address this issue, SK-45 RCC cells were pre-treated with sorafenib for $3 \mathrm{~h}$ followed by the addition of LDL, or in the reverse order. There was no significance in the order of treatment (Figure 2A). Importantly, the pre-treatment with sorafenib had no effect on the LDL-mediated AKT phosphorylation (Figure 2B). The addition of either AKT inhibitor IV or PI3K inhibitor LY294002 completely inhibited the viability of SK-45 and PNX0010 cells simultaneously treated with sorafenib and LDL (Figure 2C). The addition of LDL also increased PI3K-dependent activation of MEK/ERK signalling in SK-45 and PNX0010 cells (Figure 2D). However, the potential role of MEK/ERK signalling in LDL-mediated TKI resistance can be ruled out as the concomitant treatment with AKT inhibitor IV restored sensitivity of RCC cells to sunitinib in the presence of LDL
(Figure 2C), but failed to block LDL-induced activation of MEK/ ERK signalling (Figure 2D).

Lipid rafts mediate AKT-dependent pro-survival signalling (Zhuang et al, 2002; Oh et al, 2007). The disruption of lipid rafts with HPCD completely ablated LDL-mediated AKT phosphorylation in SK-45 and PNX0010 cells (Figure 2E), suggesting the promising potential of lipid rafts as therapeutic targets. We also noted that the addition of PI3K inhibitor LY294002 completely inhibited LDL-induced AKT phosphorylation in both cell lines (Figure 2E).

Finally, we examined the effect of a high-fat/high-cholesterol diet on the growth of RCC xenograft tumours in mice treated with sunitinib. Mice fed TD.96121 diet (21\% milk fat with $1.25 \%$ added cholesterol) had elevated serum LDL and total cholesterol levels compared to mice fed regular 2018SX diet (Figure 3A). Treatment with sunitinib was effective in inhibiting the growth of PNX0010 xenograft tumours in mice on 2018SX diet (Figure 3B). In contrast, the same treatment was ineffective against PNX0010 tumours 


\begin{tabular}{|c|c|c|c|}
\hline A & Total cholesterol, $\mathrm{mg} \mathrm{dl}^{-1}$ & LDL, $\mathrm{m} \mathrm{dl}^{-1}$ & HDL, $\mathrm{mg} \mathrm{d}^{-1}$ \\
\hline $2018 \mathrm{SX}$ & $180 \pm 11.0^{*}$ & $15.3 \pm 2.2^{*}$ & $95 \pm 14.8$ \\
\hline TD.96121 & $288 \pm 36.5^{\star}$ & $40.3 \pm 6.1^{*}$ & $118.3 \pm 16.8$ \\
\hline
\end{tabular}

B

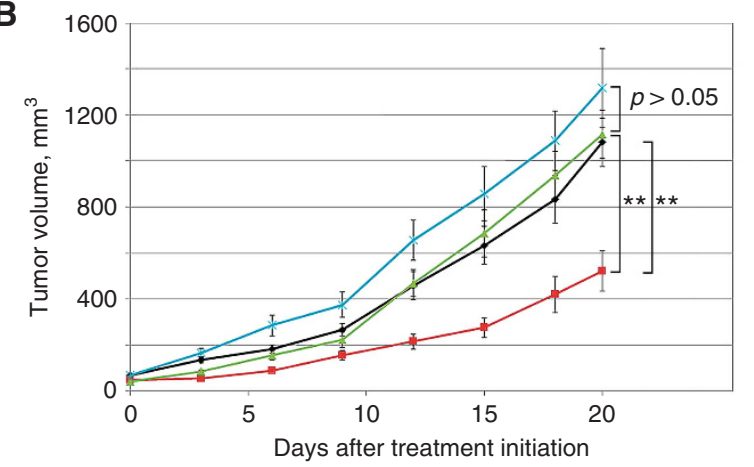

$\curvearrowleft$ 2018SX diet
$-2018 S X$ diet + sunitinib
$*$ TD.96121 diet
$\leftarrow$ TD.96121 diet + sunitinib

C

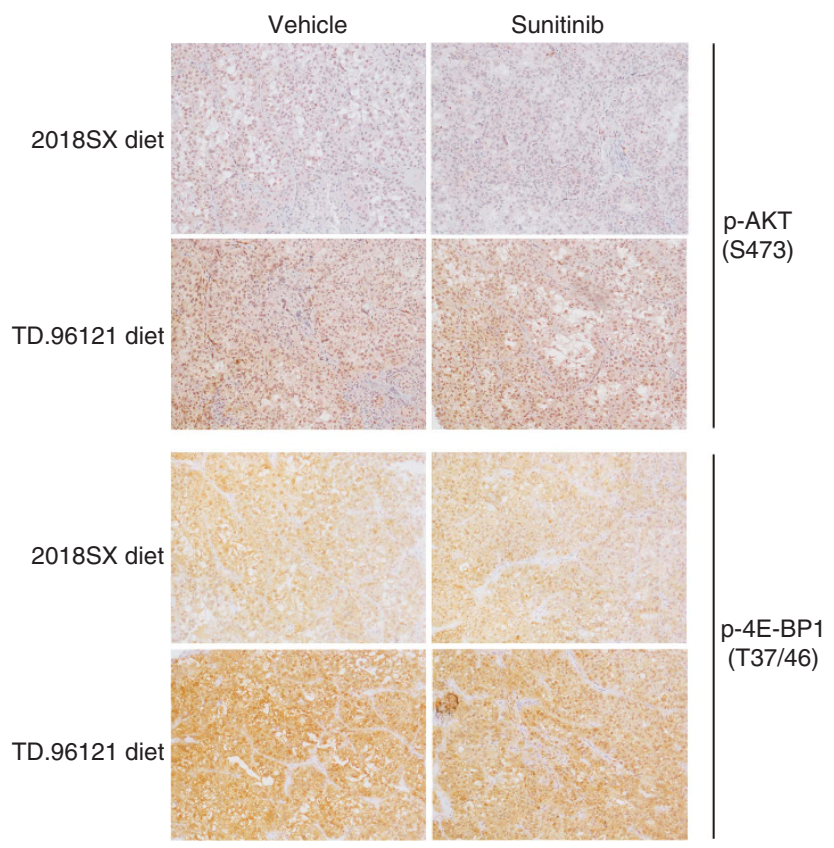

Figure 3. The effect of sunitinib on the growth of PNX0010 xenograft tumours in mice on TD.96121 or 2018SX diets. (A) Serum LDL, HDL, and total cholesterol levels in mice on high-fat/high-cholesterol TD.96121 and regular 2018SX diets. Mean \pm s.e.m., $n=5, t$-test. * $P<0.05$. (B) The effect of TD.96121 diet on the growth of PNX0010 xenograft tumours in mice treated with sunitinib. Mean \pm s.e.m., $n=5, t$-test. ${ }^{\star *} P<0.005$. (C) Immunohistochemistry of representative sections of PNX0010 xenograft tumours stained for P-AKT (S473) and its downstream effector p-4E-BP1 (T37/46).

growing in mice on TD.96121 diet (Figure 3B). Notably, AKT signalling was increased in tumours grown in mice fed TD.96121 diet, compared to mice fed 2018SX diet (Figure 3C).

\section{DISCUSSION}

The results of our experiments suggest that LDL compromises TKI-mediated cytotoxicity at least in part via augmented activation of PI3K/AKT signalling. The precise mechanism of cholesterolmediated AKT activation is unclear. Studies by Preiss et al (2007) reveal a critical role for classical PKC in activating AKT by phospholipase-modified LDL. Conversely, studies by Adam et al (2007) demonstrate that AKT itself is cholesterol sensitive as a result of the localisation of an AKT subpopulation within lipid raft microdomains. Cancer cells adapt to maintain high intracellular cholesterol levels through various mechanisms including augmented endogenous production of cholesterol regulated by the sterol response element-binding proteins (SREBPs) and increased cellular uptake of LDL (Gabitova et al, 2014). Increased sterol concentrations activate sterol-sensing liver $\mathrm{X}$ receptors (LXRs). Activated LXRs reduce intracellular cholesterol through the expression of cholesterol efflux proteins (El Roz et al, 2013; Gabitova et al, 2014). Liver X receptors also reduce uptake of the LDL cholesterol via the transcription of an E3 ubiquitin ligase, inducible degrader of LDLR (Scotti et al, 2013; Gabitova et al, 2014). All these features make SREBP and LXR pathways attractive potential targets for anticancer therapy.

Future studies will be needed to investigate if lowering blood levels of LDL cholesterol could benefit the RCC patients in conjunction with the TKIs-based therapeutic regimens.

\section{ACKNOWLEDGEMENTS}

This work was supported in part by the National Institutes of Health Grants (RO1 CA134463, RO3 CA167671), FCCC/Temple 
University Nodal Grant, and FCCC/Temple University Interdisciplinary Translational Cancer Research Grant to VMK. We acknowledge the support of the Laboratory Animal and the Histopathology Facilities at Fox Chase Cancer Center.

\section{CONFLICT OF INTEREST}

The authors declare no conflict of interest.

\section{REFERENCES}

Adam RM, Mukhopadhyay NK, Kim J, Di Vizio D, Cinar B, Boucher K, Solomon KR, Freeman MR (2007) Cholesterol sensitivity of endogenous and myristoylated Akt. Cancer Res 67(13): 6238-6246.

Adelaiye R, Ciamporcero E, Miles KM, Sotomayor P, Bard J, Tsompana M, Conroy D, Shen L, Ramakrishnan S, Ku SY, Orillion A, Prey J, Fetterly G, Buck M, Chintala S, Bjarnason GA, Pili R (2015) Sunitinib dose escalation overcomes transient resistance in clear cell renal cell carcinoma and is associated with epigenetic modifications. Mol Cancer Ther 14(2): 513-522.

Buczek M, Escudier B, Bartnik E, Szczylik C, Czarnecka A (2014) Resistance to tyrosine kinase inhibitors in clear cell renal cell carcinoma: from the patient's bed to molecular mechanisms. Biochim Biophys Acta 1845(1): 31-41.

Canter D, Kutikov A, Golovine K, Makhov P, Simhan J, Uzzo RG, Kolenko VM (2011) Are all multi-targeted tyrosine kinase inhibitors created equal? An in vitro study of sunitinib and pazopanib in renal cell carcinoma cell lines. Can J Urol 18(4): 5819-5825.

El Roz A, Bard JM, Huvelin JM, Nazih H (2013) The anti-proliferative and pro-apoptotic effects of the trans9, trans11 conjugated linoleic acid isomer on MCF-7 breast cancer cells are associated with LXR activation. Prostaglandins Leukot Essent Fatty Acids 88(4): 265-272.

Gabitova L, Gorin A, Astsaturov I (2014) Molecular pathways: sterols and receptor signaling in cancer. Clin Cancer Res 20(1): 28-34.

Golovine K, Makhov P, Uzzo RG, Shaw T, Kunkle D, Kolenko VM (2008) Overexpression of the zinc uptake transporter hZIP1 inhibits nuclear factor-kappaB and reduces the malignant potential of prostate cancer cells in vitro and in vivo. Clin Cancer Res 14(17): 5376-5384.

Gotink KJ, Broxterman HJ, Labots M, de Haas RR, Dekker H, Honeywell RJ, Rudek MA, Beerepoot LV, Musters RJ, Jansen G, Griffioen AW, Assaraf YG, Pili R, Peters GJ, Verheul HM (2011) Lysosomal sequestration of sunitinib: a novel mechanism of drug resistance. Clin Cancer Res 17(23): 7337-7346.
Gotink KJ, Verheul HM (2010) Anti-angiogenic tyrosine kinase inhibitors: what is their mechanism of action? Angiogenesis 13(1): 1-14.

Kirsanov KI, Kotova E, Makhov P, Golovine K, Lesovaya EA, Kolenko VM, Yakubovskaya MG, Tulin AV (2014) Minor grove binding ligands disrupt PARP-1 activation pathways. Oncotarget 5(2): 428-437.

Makhov PB, Golovine K, Kutikov A, Teper E, Canter DJ, Simhan J, Uzzo RG, Kolenko VM (2012) Modulation of Akt/mTOR signaling overcomes sunitinib resistance in renal and prostate cancer cells. Mol Cancer Ther 11(7): 1510-1517.

Oh HY, Lee EJ, Yoon S, Chung BH, Cho KS, Hong SJ (2007) Cholesterol level of lipid raft microdomains regulates apoptotic cell death in prostate cancer cells through EGFR-mediated Akt and ERK signal transduction. Prostate 67(10): 1061-1069.

Park K, Lee JL, Park I, Park S, Ahn Y, Ahn JH, Ahn S, Song C, Hong JH, Kim CS, Ahn H (2012) Comparative efficacy of vascular endothelial growth factor (VEGF) tyrosine kinase inhibitor (TKI) and mammalian target of rapamycin (mTOR) inhibitor as second-line therapy in patients with metastatic renal cell carcinoma after the failure of first-line VEGF TKI. Med Oncol 29(5): 3291-3297.

Preiss S, Namgaladze D, Brune B (2007) Critical role for classical PKC in activating Akt by phospholipase A2-modified LDL in monocytic cells. Cardiovasc Res 73(4): 833-840.

Rini BI (2010) New strategies in kidney cancer: therapeutic advances through understanding the molecular basis of response and resistance. Clin Cancer Res 16(5): 1348-1354.

Scotti E, Calamai M, Goulbourne CN, Zhang L, Hong C, Lin RR, Choi J, Pilch PF, Fong LG, Zou P, Ting AY, Pavone FS, Young SG, Tontonoz P (2013) IDOL stimulates clathrin-independent endocytosis and multivesicular body-mediated lysosomal degradation of the low-density lipoprotein receptor. Mol Cell Biol 33(8): 1503-1514.

Shuch B, Amin A, Armstrong AJ, Eble JN, Ficarra V, Lopez-Beltran A, Martignoni G, Rini BI, Kutikov A (2015) Understanding pathologic variants of renal cell carcinoma: distilling therapeutic opportunities from biologic complexity. Eur Urol 67(1): 85-97.

Xin H, Zhang C, Herrmann A, Du Y, Figlin R, Yu H (2009) Sunitinib inhibition of Stat3 induces renal cell carcinoma tumor cell apoptosis and reduces immunosuppressive cells. Cancer Res 69(6): 2506-2513.

Zhuang L, Lin J, Lu ML, Solomon KR, Freeman MR (2002) Cholesterol-rich lipid rafts mediate akt-regulated survival in prostate cancer cells. Cancer Res 62(8): 2227-2231.

This work is published under the standard license to publish agreement. After 12 months the work will become freely available and the license terms will switch to a Creative Commons AttributionNonCommercial-Share Alike 4.0 Unported License. 